central hyperdensity on CT is most likely explained by the pathologic finding of a dense, tenacious substance filling the center of the mass. Distinguishing features between mitral annular abscess and caseous calcification include the lack of larger amounts of calcification in the case of mitral abscesses. ${ }^{4} \mathrm{~A}$ cardiac tumor can be ruled out on CT by the lack of soft-tissue density and absence of contrast enhancement.

In summary, caseous calcification represents a rare, underappreciated variant of mitral annular calcification that should be differentiated from an abscess or tumor. It is likely that the growing clinical use of cardiac CT may increasingly uncover this rare entity.

\section{References}

1. Harpaz D, Auerbach I, Vered Z, Motro M, Tobar A, Rosenblatt S. Caseous calcification of the mitral annulus: a neglected, unrecognized diagnosis. J Am Soc Echocardiogr. 2001;14:825-31.

2. Pomerance A. Pathological and clinical study of calcification of the mitral valve ring. J Clin Pathol. 1970;23:354-61.

3. Novaro GM, Griffin BP, Hammer DF. Caseous calcification of the mitral annulus: an underappreciated variant. Heart. 2004;90:388.

4. Kronzon I, Winer HE, Cohen ML. Sterile, caseous mitral anular abscess. J Am Coll Cardiol. 1983;2:186-90.

5. Teja K, Gibson RS, Nolan SP. Atrial extension of mitral annular calcification mimicking intracardiac tumor. Clin Cardiol. 1987;10: 546-8.

\title{
Giant metastatic myxoid liposarcoma of the mediastinum: A case report
}

\author{
Gabriele Di Giammarco, MD, Michele Di Mauro, MD, Marco Pano, MD, Sergio Cirmeni, MD, Marco Contini, MD, \\ Carlo Di Lorenzo, MD, Antonio Bivona, MD, and Gerardo Liberti, MD, Chieti, Italy
}

$\mathrm{M}$ yxoid liposarcoma is a very uncommon primary neoplasm in the mediastinum, representing $9 \%$ of all primary sarcomas in this area. ${ }^{1,2}$ It develops preferentially in the lower extremities $(75 \%)$ and less frequently in the retroperitoneum. ${ }^{1}$ Myxoid liposarcoma usually metastasizes in the lungs and bone, ${ }^{1}$ and rarely in the mediastinum. ${ }^{3}$ The time interval between the first presentation and the pericardial metastasis ranges from 7 to 25 years. ${ }^{1}$ A case of giant metastatic myxoid liposarcoma in the pericardium causing cardiac tamponade is reported.

\section{Clinical Summary}

A 62-year-old man underwent 3 resections of a primary myxoid liposarcoma of the left thigh in 1983, 1985, and 1989. He was admitted to the hospital with reports of dyspnea for the previous 3 weeks and chest pain of recent onset. The computed tomography (CT) scan performed 6 months previously at a follow-up examination did not show any metastasis. No abnormalities were evident on the electrocardiogram. The chest radiography revealed a widened mediastinum. Echocardiography showed a big mass in the pericardium compressing the right sections of the heart. The CT scan confirmed the presence of a mediastinal mass with dimen-

\footnotetext{
From the Division of Cardiac Surgery, University “G D'Annunzio," ChietiPescara, Chieti, Italy.

Received for publication Dec 10, 2004; accepted for publication Jan 10, 2005.

Address for reprints: Gabriele Di Giammarco, MD, Chief of Division of Cardiac Surgery, University "G D'Annunzio," S Camillo Hospital, v Forlanini 50, 66100 Chieti, Italy (E-mail: gabriele.digiammarco1@tin.it).

J Thorac Cardiovasc Surg 2005;129:1440-2

$0022-5223 / \$ 30.00$

Copyright $\odot 2005$ by The American Association for Thoracic Surgery

doi:10.1016/j.jtcvs.2005.01.010
}

sions of $23.5 \times 18.0 \times 15.0 \mathrm{~cm}$ (Figure 1). On the same day, the patient underwent surgical resection.

After the chest was opened through a median sternotomy, the pericardium appeared very tense and consistently hard. The pericardium was incised, starting from a cranial point where the surface was less tense. Soon after, we noticed that the inferior surface of the heart was displaced cranially to the mid-transverse line of the anterior mediastinum. The majority of the pericardium was occupied by the neoplasm, and the heart appeared undersized. The tumor was free from adhesions throughout the entire circumference except for a small area infiltrating the inferior wall of the right ventricle close to the apex. Cardiopulmonary bypass was established with both venae cavae cannulated. Myocardial protection was achieved by intermittent antegrade warm blood cardioplegia. The mass was easily dissected from the diaphragm. The infiltrating area was extensively resected over normal muscle, and the ventriculotomy was repaired with an equine pericardial patch $(8.0 \times 6.0 \mathrm{~cm})($ Edwards LifeSciences LLC, Irvine, Calif) sutured with a running 4-0 Prolene suture (Ethicon, Somerville, NJ).

The patient had an uneventful postoperative recovery and was discharged on the fifth postoperative day. The first CT did not show any recurrence of the tumor.

The resected mass measured $21.0 \times 17.0 \times 15.0 \mathrm{~cm}$ and weighed $2430 \mathrm{~g}$. It was yellowish and mainly encapsulated except for the infiltrating area. The cut surface revealed myxoid and necrotic areas. Microscopy showed prevalent myxoid stroma containing lipoblasts and myocytes in the infiltrating area (Figure 2). It was labeled grade I, with the percentage of round cells less than $10 \%{ }^{1}$

\section{Discussion}

Wong and colleagues ${ }^{4}$ reported a case of a 54-year-old patient with a previously resected liposarcoma of the left pectoralis muscle who underwent operation for a metastatic tumor located in the anterior mediastinum and measuring $18 \times 14 \mathrm{~cm}$. They stated that the 


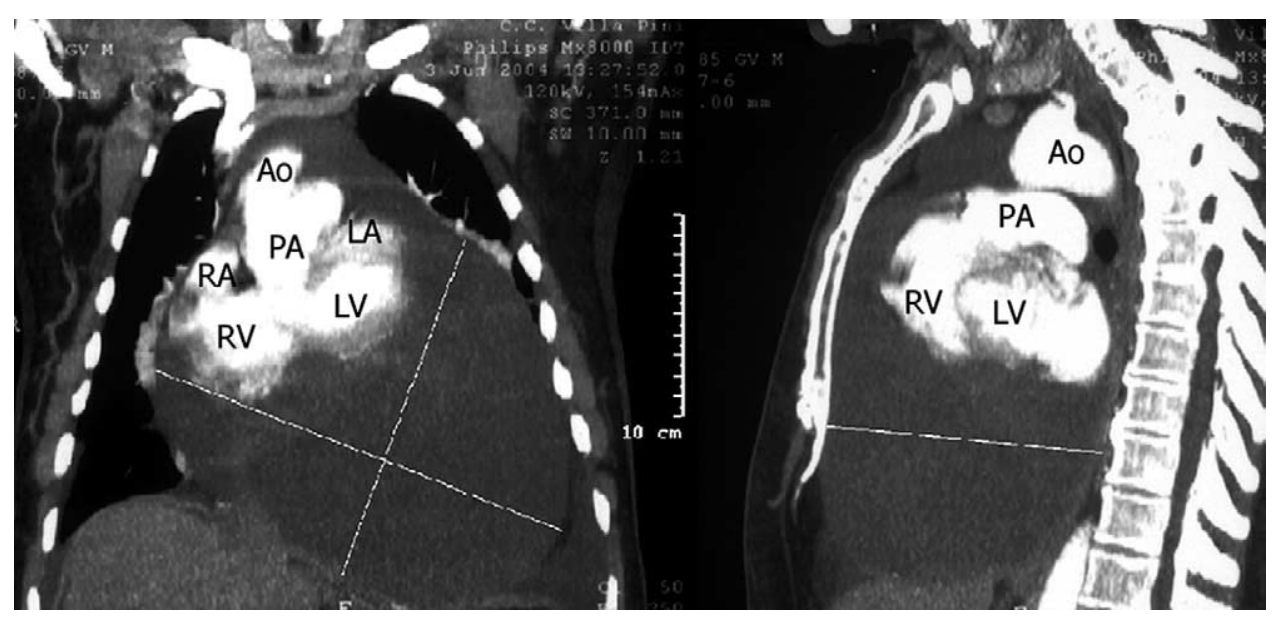

Figure 1. Preoperative computed tomography (CT) scan showed a mediastinal mass with dimensions of $23.5 \times 18.0$ $\times 15.0 \mathrm{~cm}$. Ao, Aorta; $R A$, right atrium; $P A$, pulmonary artery; $L A$, left atrium; $R V$, right ventricle; $L V$, left ventricle.

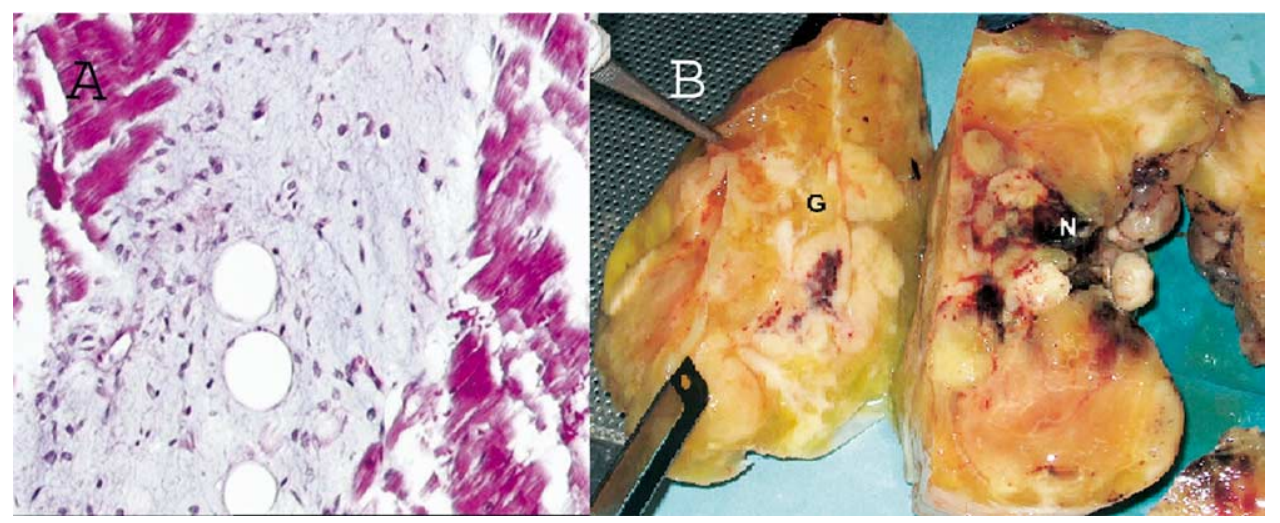

Figure 2. Cut surface revealed myxoid and necrotic areas (A). Histologic section of the infiltrating area (hematoxylin-eosin, $\times 10$ ) demonstrated a myxoid stroma containing lipoblasts and myocytes (B). G, Gelatinous; $N$, necrotic.

excised mass was the biggest mediastinal metastatic myxoid liposarcoma ever reported.

Myxoid liposarcoma has an expansive rather than infiltrative growth, so it can cause symptoms because of compression of the heart and great vessels. ${ }^{4}$ Symptoms are dyspnea, wheezing, and chest pain, even if the tumor grows asymptomatically. ${ }^{2}$

In our case, the patient stayed asymptomatic until 3 weeks before surgery, with a negative CT scan 6 months before. This means the described metastasis occurred long after the first presentation of the primary tumor (21 years), but developed in less than 6 months.

Although the operative mortality ranges from $12 \%$ to $40 \%,{ }^{2,5}$ surgical resection remains the only chance in these rare cases.

Patients with myxoid liposarcoma who are surgically treated demonstrate good survival even 10 years after surgery. Multivar- iate analysis individuated the presence of round cells, age $(>45$ years), and necrotic areas as independent variables for a lower survival at 10 years; the grade of the neoplasm influences the incidence of metastasis and its recurrence. ${ }^{1}$

Patients with deep-seated liposarcoma more frequently have recurrences within 6 months; the main negative factor is an incomplete resection. ${ }^{1}$

In our case, evidence of necrotic areas within the mass and age more than 45 years have to be considered unfavorable prognostic factors, but the low-grade round cells differentiation and complete resection of the tumor could provide a good survival free of recurrences.

\section{Conclusions}

Our case can be considered unique for the giant dimensions and rare location of the metastasis. Complete surgical resection repre- 
sents the only chance to improve survival and quality of life in these rare cases.

\section{References}

1. Enzinger FM, Weiss SW. Liposarcoma. In: Enzinger FM, Weiss SW, editors. Soft tissue tumors, 3rd ed. St Louis: Mosby; 1995. p. 431-66.

2. Attal H, Jensen J, Reyes CV. Myxoid liposarcoma of the anterior mediastinum. Diagnosis by fine needle aspiration biopsy. Acta Cytol. 1995;39:511-13.

3. Ng C, Stebbing J, Judson I. Cardiac metastasis from a myxoid liposarcoma. Clin Oncol (R Coll Radiol). 2001;13:384-5.

4. Wong SP, Ng CS, Wan S, Lee TW, Wan IY, Yim AP, et al. Giant metastatic myxoid liposarcoma causing cardiac tamponade: a case report. Jpn J Clin Oncol. 2002;32:480-2.

5. Kendall SW, Williams EA, Hunt JB, Petch MC, Wells FC, Milstein BB. Recurrent primary liposarcoma of the pericardium: management by repeated resections. Ann Thorac Surg. 1993;56:560-2.

\title{
Mechanical aortic valve malfunction: An intraoperative BioGlue complication
}

\author{
Mohsen Karimi, MD, ${ }^{a}$ Richard E. Kerber, MD, ${ }^{\mathrm{b}}$ and Jeffrey E. Everett, MD, ${ }^{a}$ lowa City, lowa
}

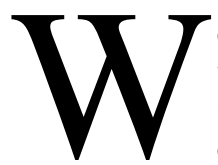

e report a case of intraoperative mechanical aortic valve malfunction after application of BioGlue (Cryolife, Inc, Kennesaw, Ga) over the aortotomy closure.

\section{Clinical Summary}

A 62-year-old woman, weighing $48 \mathrm{~kg}$, with symptomatic combined aortic stenosis and insufficiency presented for elective valve replacement.

After median sternotomy, the aorta was cannulated, and a single dual-stage venous cannula was placed through the right atrial appendage. Antegrade and retrograde cold blood cardioplegia with moderate core hypothermia $\left(32^{\circ} \mathrm{C}\right)$ constituted the cardioprotective strategy. The left ventricle was vented through the right superior pulmonary vein. Exposure of the aortic valve was obtained through a transverse aortotomy. The valve was severely calcified. The valve was excised in its entirety and calcium debrided. The patient's native root was small, and the annulus size was $19 \mathrm{~mm}$. A 19-mm St Jude Regent Mechanical valve (St Jude Medical, Inc, St Paul, Minn) was chosen because it would provide acceptable hemodynamics. The valve was seated into position successfully, and each of the leaflets moved freely. The aortotomy was next closed in 2 layers with 4-0 Prolene suture (Ethicon, Inc, Somerville, NJ). The suture line was checked for integrity with administration of cardioplegia in antegrade fashion. The closure appeared hemostatic with the

\footnotetext{
From the Division of Cardiothoracic Surgery ${ }^{\mathrm{a}}$ and Division of Cardiology, ${ }^{\mathrm{b}}$ University of Iowa College of Medicine, Iowa City, Iowa.

Received for publication Oct 19, 2004; accepted for publication Nov 4, 2004.

Address for reprints: Jeffrey E. Everett, MD, Division of Cardiothoracic Surgery, The University of Iowa Hospitals and Clinics, Iowa City, IA 52242 (E-mail: jeffrey-everett@uiowa.edu).

J Thorac Cardiovasc Surg 2005;129:1442-3

$0022-5223 / \$ 30.00$

Copyright (C) 2005 by The American Association for Thoracic Surgery doi:10.1016/j.jtcvs.2004.11.057
}

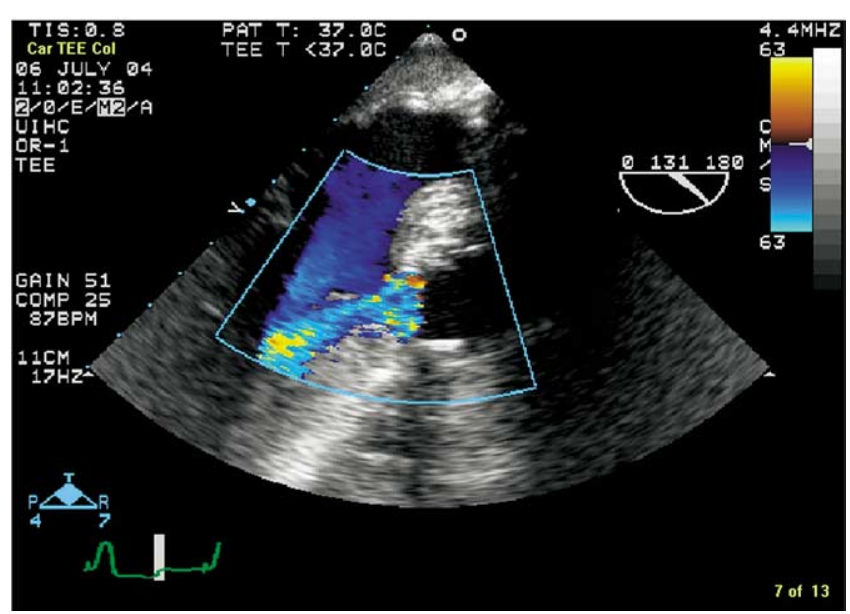

Figure 1. Aortic insufficiency after BioGlue (Cryolife, Inc, Kennesaw, Ga) application.

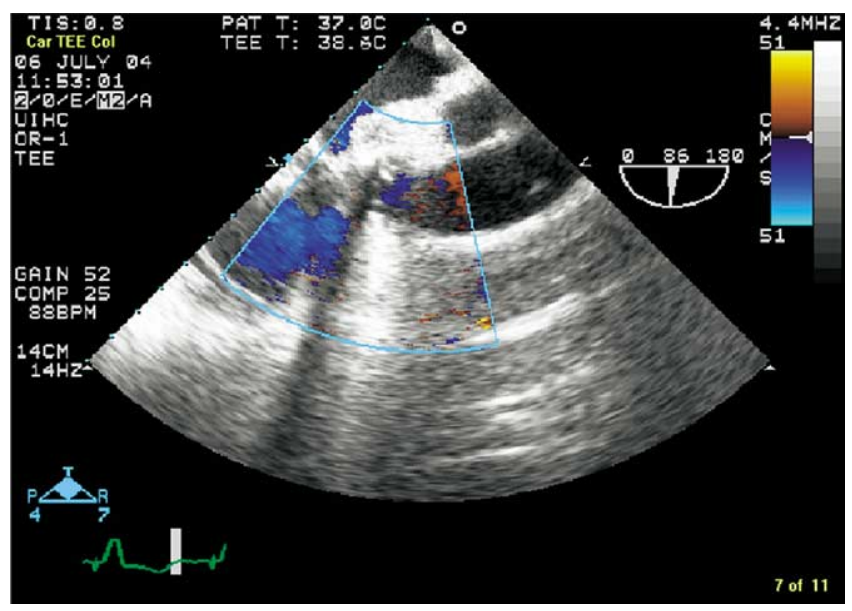

Figure 2. Restoration of valve function after removal of BioGlue. 